\title{
Mental health: the forgotten aspect of the COVID-19 pandemic
}

Behshid Garrusi, ${ }^{1}$ Ali Amirkafi ${ }^{2}$ and Saideh Garousi ${ }^{3}$

${ }^{1}$ Department of Social Medicine, Neurosciences Research Center, Institute of Neuropharmacology, Kerman University of Medical Sciences, Kerman, Islamic Republic of Iran. ${ }^{2}$ Iran University of Medical Sciences, Tehran, Islamic Republic of Iran. ${ }^{3}$ Department of Social Sciences, Shahid Bahonar University, Kerman, Islamic Republic of Iran. (Correspondence to: behshidgarrusi@gmail.com; Bgarrusi@kmu.ac.ir).

Citation: Garrusi B; Amirkafi A; Garousi S. Mental health: the forgotten aspect of the COVID-19 pandemic. East Mediterr Health J. 2020;26(10):1151-1154. https://doi.org/10.26719/emhj.20.117

Received: 23/03/20; accepted: 27/08/20

Copyright (C) World Health Organization (WHO) 2020. Open Access. Some rights reserved. This work is available under the CC BY-NC-SA 3.0 IGO

license (https://creativecommons.org/licenses/by-nc-sa/3.o/igo)

\section{Introduction}

Since the start of the COVID-19 outbreak, most countries in the Region have been affected and the lives of millions have been fundamentally altered (1). Moreover, prolonged disasters, such as the COVID-19 pandemic, can increase psychological pressures that may lead to more severe mental complications (2).

During disasters people normally will look to help to each other; however, there also needs to be scientific, holistic and planned approaches implemented by health policy-makers in order to enhance the status of mental well-being in society. New studies suggest that these interventions should be established based on the type and severity of the situation as well as taking into consideration cultural norms (3). Historically, examples of two main interventions to improve a population's mental health after a disaster took place in the Islamic Republic of Iran and Japan after a devastating earthquake and a tsunami, respectively.

The Islamic Republic of Iran is prone to natural disasters due to its geography and seismic activity (4). The Bam and Kermanshah earthquakes, as well as incidences of severe flooding, are among examples in recent times. The mental health interventions following the Bam earthquake (2003) were very successful. However, these interventions are more applicable for acute, sudden incidences such as earthquakes, and not for chronic disasters such as the current COVID-19 pandemic.

Currently, countries are finding their healthsystems on the frontline in the fight against COVID-19 (5). The lack of successful mental health interventions during the COVID-19 pandemic in the Eastern Mediterranean Region has highlighted the necessity to develop a model appropriate for Iranian society.

To develop this model we used a qualitative methodology with a grounded theory approach. Data were gathered from 12 experts in the fieldsof psychiatry, psychology and sociology using semistructured interviews. The research aim was explained to participants and informed consent was obtained for audio recordings or written viewpoints.

The following question, based on health system structure and sociocultural background $(6,7)$, was used: "What variables should be used during the COVID-19 outbreak for promoting mental well-being?" This fundamental query was broken down into two further questions: 1) What characteristics of Iranian society and its health system can be used to promote mental wellbeing? 2) What sort of people are effective in improving mental well-being?

The basic strategy of the data analysis in grounded theory includes three coding methods, i.e. open, axial and selective (8). The data were broken into discrete parts and reduced to concepts, thus creating categories. During the axial coding, extracted categories were related to subcategories through reconnection of the data. During the third stage, i.e. selective coding or "the process of integrating and refining categories" (8), the core category is extracted. For final agreement,we discussed the categories according to several sections.

We performed the following steps based on Morse (2002)classification (9): 1) Matching the question, method, data and analytical procedures; 2) Invitation of experts to check appropriateness of the sample (10); and 3) To ensure that the study met the reliability criteria, through review and approval of results by an expert not related to the study. The interview data were analyzed in multiple stages. Obtained data are presented in Table 1.

\section{Sociocultural characteristics of Iranian society}

\section{Family social capital}

Deep and trustworthy relationships between family members can act as a shield against adverse psychological impacts during outbreaks. As stated by one expert, "Family structure in our society was able to help improve mental health during wartime, in crises such as earthquakes and floods."

\section{Neighbourhood social capital}

The social structure of the neighbourhood is related to factors such as having trust, sense of belonging, and security.

\section{Informal groups social capital (social networks)}

Membership of different groups helps to increase social capital through social networking. One expert stated that, 


\begin{tabular}{|c|c|c|c|}
\hline Core theme & Main categories & Subcategories & Codes \\
\hline \multirow{8}{*}{$\begin{array}{l}\text { Connection between } \\
\text { formal health system } \\
\text { services and social and } \\
\text { cultural potentials }\end{array}$} & \multirow[t]{5}{*}{$\begin{array}{l}\text { Sociocultural characteristics of } \\
\text { Iranian society }\end{array}$} & Family social capital & $\begin{array}{l}\text { Cohesive family relationships, } \\
\text { mutual trust, cooperation between } \\
\text { family members. }\end{array}$ \\
\hline & & Neighbourhood social capital & $\begin{array}{l}\text { Mutual trust, formal and informal } \\
\text { participation, similar norms of } \\
\text { behaviour. }\end{array}$ \\
\hline & & $\begin{array}{l}\text { Informal groups social capital (social } \\
\text { networks) }\end{array}$ & $\begin{array}{l}\text { Membership ofsports and religious } \\
\text { groups, peer groups. }\end{array}$ \\
\hline & & The role of reference groups & $\begin{array}{l}\text { Teachers, religious leaders, sports and } \\
\text { cultural role models. }\end{array}$ \\
\hline & & Use of media & $\begin{array}{l}\text { Television, radio, social media, virtual } \\
\text { media. }\end{array}$ \\
\hline & \multirow{3}{*}{$\begin{array}{l}\text { Characteristics of the Iranian health } \\
\text { system }\end{array}$} & Health network system & "Health homes" Behvarzan \\
\hline & & Volunteer groups & Rabetine, health centre \\
\hline & & Professional mental health workers & $\begin{array}{l}\text { Psychologists, psychiatrists, mental } \\
\text { health nurses, } \\
\text { social workers }\end{array}$ \\
\hline
\end{tabular}

"Sense of belonging to a social group, social trust and involvement are the key features of social capital that can be used to maximize the efficacy of mental health interventions." Considering the high power of social capital in the Islamic Republic of Iran, community-based crisis response management can be very helpful (11).

\section{Reference groups}

Various studies show that public trust in reference groups is strong, therefore their help can be very effective (7-12). For example, religious leaders can take two critical actions: maintaining peace and helping to disseminate health advice (13).

One expert stated that, "If a football player, a famous actor or a well-respected religious leader tries to teach people how to identify and treat mental health problems during a crisis, then mental health programmes will take a few steps forward in the actual event of a crisis." One of the Islamic Republic of Iran's success stories has been accessing help from teachers to reduce the burden of mental health problems.

\section{Use of media}

Receiving reliable news about the situation and advice on reducing anxiety is critical. One expert stated, "People need to learn to distinguish right from wrong. If they can make that distinction, they will be less likely to be in a state of crisis."

\section{Characteristics of the Iranian health system}

The structure of the Iranian health system operates through a variety of networks. One important part of this system is "Health homes" and trained workers (Behvarze). The country's health system can be reviewed at four levels: village, city, province and nation. A hierarchical structure could lead to better service delivery.

\section{Volunteer groups}

Skilled women volunteers (Rabetin) can collaborate with the Iranian Ministry of Health on neighbourhood plans to help and rehabilitate people in crisis. As one psychiatrist stated: "Why do we ignore the volunteer health assistants that have been assisting health programmes for more than 25 years in urban areas?"

\section{Professional mental health workers}

A former health manager stated that, "In the Mental Health Office of the Ministry of Health, there are specialized personnel including psychologists, psychiatrists, and social workers. Some of the goals of this unit include preventing or reducing mental health complications after unexpected events and increasing the ability to cope among survivors.

The core theme of the research emerged as "Connection between formal health system services and sociocultural potentials." This theme highlights the connection between the capabilities of the formal health care system and the social and cultural system.

\section{Discussion}

The conceptual model shows the important elements required for a mental health intervention programme. Expert opinion confirms that the current health system is not enough to support mental health well-being. Close relationships between multiple societal elements ultimately lead to the connection between formal health structures and the sociocultural system.

Since the COVID-19 outbreak, the contributing effects of social media, reference groups and social capital on the promotion of mental health must be considered. Various types of social capital increase the likelihood of volunteers participating in health programmes. Reference groups contribute to the promotion of social capital in society and use social media to convey messages more easily 
and quickly. This sociocultural structure has a profound effect on the health system. Health networks, through social media, have enhanced both intra-structural and extra-structural influences. Social media can promote awareness of the importance of volunteering and its impact on mental well-being. Reference groups have a similar function and also encourage people to volunteer. Professional mental health workers enrich reference groups' messages through specific clinical information. In addition, there is a similar relationship between professional mental health workers and volunteers. In order to conduct a successful promotion of mental health well-being during the current COVID-19 outbreak, the following model is suggested (Figure 1).

\section{Conclusion}

Many health studies have been conducted in the Region since the outbreak of COVID-19 (14-18). However, mental health promotion should be considered as a priority. This study attempted to provide an appropriate and cost-effective model based on views of experts in this field, focusing on mental health well-being intervention programmes that focus on the sociocultural context of each community (19).

Figure 1 Conceptual model for mental health well-being during the COVID-19 pandemic

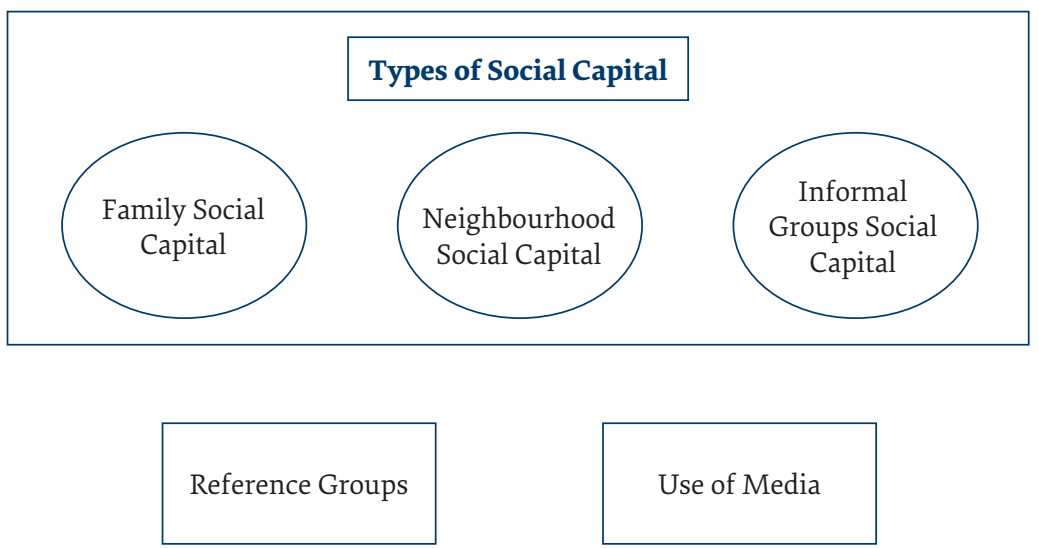

Social Factors
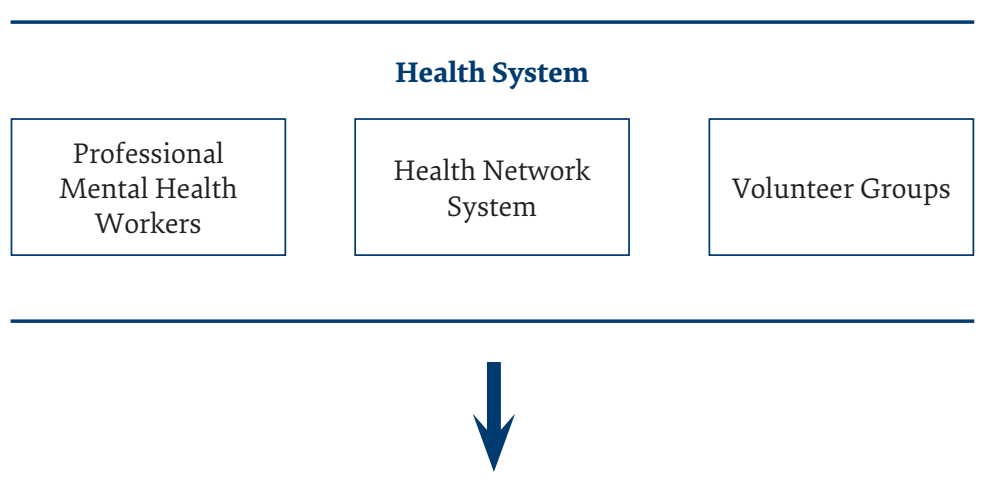

Connection between formal health system services and social and cultural potentials 


\section{References}

1. Al-Mandhari A; Samhouri D; Abubakar A; Brennan R. Coronavirus Disease 2019: preparedness and readiness of countries in the Eastern Mediterranean Region. East Mediterr Health J. 2020;26(2):136-137. https://doi.org/10.26719/2020.26.2.136

2. 2-Xiang YT, Yang Y, Li W, Zhang L, Zhang Q, Cheung T, et al. Timely mental health care for the 2019 novel coronavirus outbreak is urgently needed. Lancet Psychiatry. 2020;7(3):228-229.

3. Diaz JP, Srinivasa Murthy R, Lakshminarayana R. Advances in disaster mental health and psychosocial support. American Red Cross, New Delhi 2006.

4. Ardalan A; Yusefi H; Rouhi N; Banar A; Sohrabizadeh S. Household disaster preparedness in the Islamic Republic of Iran: 2015 estimation. East Mediterr Health J. 2019;25(x):xxx-xxx. https://doi.org/10.26719/emhj.19.048 (In Press).

5. Kang L, Li Y, Hu S, Chen M, Yang C, Yang BX, et al. The mental health of medical workers in Wuhan, China dealing with the 2019 novel coronavirus. Lancet Psychiatry. 2020 Mar;7(3):e14. doi:10.1016/S2215-0366(20)30047-X.

6. Yasamy MT, Shahmohammadi D, Bagheri Yazdi SA, Layeghi H, Bolhari J, Razzaghi EM, et al. Mental health in the Islamic Republic of Iran: achievements and areas of need. East Mediterr Health J.2001;7:381-91

7. Yasamy MT, Zojaji A, Mirabzade A, Bagheri Yazdi SA, Layeghi H, Shojaee AM, et al. Determination of appropriate methods of mental health service delivery to survivors of natural disasters. (In Persian). National Committee for Disaster Reduction 1997.

8. Strauss A, Corbin J. Basics of qualitative research: grounded theory; procedures and techniques. Thousand Oaks: Sage Publishing; 1998.

9. Morse JM, Barrett M, Mayan M, Olson K, Spiers J. Verification strategies for establishing reliability and validity in qualitative research. Int J Qual Methods. 2002;1(2):13-22.

10. Morse JM. Strategies for sampling. In: Morse, J. (ed.) Qualitative nursing research: a contemporary dialogue. Newbury Park: Sage Publications; 1991:117-131.

11. Roudini J, Khankeh HR, Witruk E, Ebadi A, Reschke K, Stück M. Community mental health preparedness in disasters: a qualitative content analysis in an Iranian context. HDQ. 2017;2(4):165-178.

12. Ostadtaghizadeh A, Ardalan A, Paton D, Khankeh H, Jabbari H. Community disaster resilience: a qualitative study on Iranian concepts and indicators. Nat Hazards. 2016;83:1843-1861.

13. Liu S, Yang L, Zhang C, Xiang YT, Liu Z, Hu S, et.al. Online mental health services in China during the COVID-19 outbreak. Lancet Psychiatry. 2020;7(4):17-18.

14. Al-Mandhari A; Kodama C; Abubakar A; Brennan R. Solidarity in response to COVID-19 outbreak in the Eastern Mediterranean Region. East Mediterr Health J. 2020;26(5):492-494. https://doi.org/10.26719/2020.26.5.492

15. Mowafi H, Sakr H, Ravaghi H, Elmahal O, Slama S, Samhouri D, et al. Leveraging the COVID-19 response to improve emergency care systems in the Eastern Mediterranean Region. East Mediterr Health J. 2020 Jun 24;26(6):626-629. https://doi. org/10.26719/2020.26.6.626.

16. Rawaf S, Quezada Yamamoto H, Rawaf D. Unlocking towns and cities: COVID-19 exit strategy. East Mediterr Health J. 2020 May;26(5):499-502. https://doi.org/10.26719/emhj.20.028

17. Gele A. What works where in prevention of Covid-19: The case of Somalia. East Mediterr Health J. 2020 May;26(5):495-496 https://doi.org/10.26719/2020.26.5.495

18. Konings F, Barakat A, Hutin Y, Hajjeh R. COVID-19 highlights the need for a strong health laboratories foundation for infectious disease surveillance and control in the Eastern Mediterranean Region. East Mediterr Health J. 2020;26(6):633-635. https://doi. org/10.26719/emhj.20.074

19. Ardalan A, Masoomi G, Goya M, Ghaffari M, Miadfar J, Sarvar M, et al. Disaster health management: Iran's progress and challenges. Iran J Public Health 2009;38(Supple 1):93-97. 